\title{
Bloqueo ecoguiado paraesternal bilateral con catéter para manejo del dolor en cirugía cardiaca
}

\author{
Vásquez Moya JP. ${ }^{1,2}$, Paz Rodríguez V. ${ }^{1}$, Portilla Flores M. ${ }^{1,2}$, Torres Pérez D. ${ }^{1,2}$ \\ 1 Universidad de Los Andes, Santiago, Chile. \\ 2 Clínica Santa María, Santiago, Chile.
}

Introducción: El bloqueo paraesternal es una técnica regional efectiva para el manejo del dolor postesternotomía en cirugía cardiaca, dentro del protocolo ultra-fast track. Sin embargo, existen pocas series que describan su efectividad con catéter. El objetivo del estudio es describir los resultados clínicos del bloqueo paraesternal bilateral con dosis repetidas a través del catéter en cirugía cardiaca.

Métodos: Diseño: Serie de casos prospectiva. Inclusión: pacientes sometidos a cirugía cardíaca con esternotomía media o media parcial y bypass cardiopulmonar en Clínica Santa María, Chile, entre octubre de 2018 y febrero de 2019. Se excluyeron cirugías de emergencia y pacientes con infección del sitio de punción o inmunosupresión severa. Se realizó el bloqueo ecoguiado paraesternal bilateral con catéter con un bolo inicial de Chirocaína $0,25 \% 20 \mathrm{ml}$ por lado, previo a la incisión y bajo anestesia general. En el postoperatorio, se administró un bolo de Chirocaína $0,1 \% 10$ $\mathrm{ml}$ por cada catéter paraesternal cada 12 horas durante 48 horas. Se evaluó dolor con la escala visual análoga (EVA) a 24 y 48 horas, analgesia de rescate, incidencia de náuseas y vómitos, complicaciones quirúrgicas mayores y las complicaciones asociadas al catéter. Se utilizó estadística descriptiva para datos paramétricos y no paramétricos.

Resultados: Se incluyeron 60 pacientes. Las características de los pacientes y las cirugías se presentan en la Tabla 1. Nueve cirugías incluyeron más de un procedimiento. Mediana del dolor en reposo fue 2 y 1 a las 24 y 48 horas y 2 durante kinesiterapia, $81 \%$ y $100 \%$ de los pacientes presentó dolor leve a 24 y 48 horas respectivamente. Veinticinco pacientes requirieron analgesia de rescate con opioides ( 78 mcg de fentanilo) y $72 \%$ requirió rescate en dos o menos ocasiones. Incidencia de náuseas $45 \%$ y vómitos 18,3\%. Las complicaciones quirúrgicas fueron un taponamiento cardiaco reoperado y un paciente falleció por reinfarto. Las complicaciones de los catéteres fueron un corte de catéter durante el retiro, que se logra retirar completo desde el sitio de punción y un catéter que se desplaza y falla, con aumento de dolor clínicamente significativo (paciente con mayor EVA de la serie).

Conclusión: Esta serie muestra que el bloqueo paraesternal bilateral con catéter es efectivo para el manejo del dolor en cirugía cardíaca, con un número bajo de complicaciones leves. Nuevos estudios deben estar dirigidos a aumentar el número de pacientes y evaluar la técnica mediante estudios comparativos con otras técnicas de manejo del dolor.

https://doi.org/10.25237/congresoclasa2019.60 